\title{
Monitoring diaphragm activity and neuromechanical efficiency during acute respiratory failure: feasibility and preliminary findings
}

\author{
EC Goligher ${ }^{1,2,3^{*}}$, C Urrea' ${ }^{1}$, S Vorona ${ }^{1}$, LJ Brochard ${ }^{2,4}$, C Sinderby ${ }^{4}$, SS Bolz ${ }^{3}$, GD Rubenfeld ${ }^{2,5}$, BP Kavanagh ${ }^{2,3,6}$, \\ ND Ferguson 1,2,3
}

From ESICM LIVES 2015

Berlin, Germany. 3-7 October 2015

\section{Introduction}

Ventilator-induced diaphragm dysfunction is thought to result from diaphragm inactivity and/or dyssynchronous eccentric diaphragm contractions during mechanical ventilation $[1,2]$. The magnitude of diaphragm disuse and the frequency of eccentric contractions and their impact on diaphragm function remains uncertain.

\section{Objectives}

To describe the feasibility of monitoring diaphragm activity, patient-ventilator synchrony, and the efficiency of diaphragm pressure generation longitudinally during the first week of mechanical ventilation.

\section{Methods}

Patients requiring invasive mechanical ventilation due to sepsis, ARDS, or severe acute brain injury were enrolled within 24 hours of intubation. Airway pressure, flow, crural diaphragm EMG activity (Edi) and transdiaphragmatic pressure (Pdi) were recorded for 5 minutes of every hour for up to 7 days. To assess for changes in diaphragm function, neuromechanical efficiency (NME - ratio of Pdi/ Edi) was measured on a daily basis [3]. Diaphragm thickness (Tdi) and thickening fraction (TFdi) were measured once daily [4].

\section{Results}

Ten patients ( 6 female) were enrolled over 8 months: 3 were intubated for intracranial hemorrhage, 5 for pneumonia, and 2 for non-pulmonary sepsis. Five subjects completed 7 days of monitoring; 2 were successfully extubated and 3 died within 7 days (total patient-days: 52). Edi was initially very low $(<5 \mathrm{uV})$ or absent in 6 of 10 subjects and tended to increase over several days. Daily TFdi was strongly correlated with the 24-hour average value of Edi (conditional $R^{2}=0.65, p=0.04$ ). NME could not be measured on 24 patient-days (46\%) owing to the absence of Edi activity. Baseline NME varied between patients and NME decreased over time in some patients.

\section{Conclusions}

It is feasible to monitor diaphragm activity, synchrony and pressure generating efficiency longitudinally during mechanical ventilation. However, many subjects did not complete 7 days of monitoring and NME could not be measured on almost $50 \%$ of study days owing to absent diaphragm activity. Changes in diaphragm thickening fraction measured once daily reflect variation in average daily diaphragm activity.

\section{Grant Acknowledgment}

This study was supported by funding from the Physician Services Incorporated (PSI) Foundation.

\footnotetext{
Authors' details

${ }^{1}$ University Health Network, Division of Respirology, Toronto, Canada. ${ }^{2}$ University of Toronto, Interdepartmental Division of Critical Care Medicine, Toronto, Canada. ${ }^{3}$ University of Toronto, Department of Physiology, Toronto, Canada. ${ }^{4}$ St. Michaels Hospital, Keenan Centre for Biomedical Research, Toronto, Canada. ${ }^{5}$ Sunnybrook Health Sciences Centre, Department of Critical Care, Toronto, Canada. ${ }^{6}$ Hospital for Sick Children, Department of Critical Care Medicine, Toronto, Canada.
} 


\section{References}

1. Vassilakopoulos T: Ventilator-induced diaphragm dysfunction: the clinical relevance of animal models. Intensive Care Med 34(1):7-16, Jan;:

2. Gea J, Zhu E, Gáldiz JB, et al: [Functional consequences of eccentric contractions of the diaphragm]. Arch Bronconeumol 2009, 45(2):68-74, Feb;.

3. Doorduin J, van Hees HW, van der Hoeven JG, Heunks LM: Monitoring of the respiratory muscles in the critically ill. Am J Respir Crit Care Med 2013, 187(1):20-7, Jan 1:

4. Goligher EC, Laghi F, Detsky ME, et al: Measuring diaphragm thickness with ultrasound in mechanically ventilated patients: feasibility, reproducibility and validity. Intensive Care Med 2015, Feb 19 [epub ahead of print].

doi:10.1186/2197-425X-3-S1-A1002

Cite this article as: Goligher et al:: Monitoring diaphragm activity and neuromechanical efficiency during acute respiratory failure: feasibility and preliminary findings. Intensive Care Medicine Experimental 2015 3(Suppl 1): A1002.

\section{Submit your manuscript to a SpringerOpen ${ }^{\mathcal{O}}$ journal and benefit from:}

- Convenient online submission

- Rigorous peer review

- Immediate publication on acceptance

- Open access: articles freely available online

- High visibility within the field

- Retaining the copyright to your article 